\title{
Development Tendency of Detonation Transmission Technology among Long Interlayers in Oil \& Gas Well
}

\author{
Wei Yang ${ }^{1,}{ }^{*}$, Jian Tong ${ }^{1}$, Zhao Zhou ${ }^{1}$, Qinying $\mathrm{Li}^{1}$, Zheng Chen ${ }^{1}$ \\ ${ }^{1}$ Xi'an Wuhua Juneng Blasting Equipment Co., Ltd., 20th Zhuque Avenue, Xi'an, China \\ *287003016@qq.com
}

Keywords: oil \& gas well; long interlayers; detonation transmission; mechanical design, performance test

\begin{abstract}
According to the technical features of detonation transmission among long interlayers, this paper uses the new method of powder actuating function and piston restriction energy control, combines the method of liquid restricted transmission in tubing, develops pressurizing device among long interlayers. Based on multiple performance tests, the pressurizing device meets all technical requirements for application. The pressurizing device, using powder function into detonation transmission among long interlayers for the first time, achieves the engineering technical breakthrough of multi-grades perforating during one time running.
\end{abstract}

\section{Introduction}

Multi-piece interlayer perforating guns, connected for detonation transmission, is commonly used for the detonation transmission of horizontal well, inclined well with large span interlayer and conventional TCP operation. This operation technology not only requires reliable sealing of interlayer guns and transmission sub, also requires high reliability of detonating cord and booster. The length of interlayer guns and detonation cord is according to length of interlayers, therefore, the longer interlayer is, the longer detonating cord is needed, the higher probability of failure will be. Baffle detonation transmission device is normally used in both sides of interlayer guns so as to increase the reliability and safety of detonation transmission, however, this method not only increases operation cost but also cannot radically solve the existing unreliability of detonating cord in long interlayer's detonation transmission ${ }^{[1]}$. Simultaneously, sealing problem must be resolved in long interlayer when using interlayer gun and detonating cord for detonation transmission. Taking a 100 meters interlayer for example: it will add 50 sealing point and 50 transmission points when using 25 pieces of guns and 25 sets of transmission subs, for this reason, the longer interlayer is, the more sealing point and transmission points are, the worse reliability will be. Conventional detonation transmission string among interlayer is showing as Fig. 1.

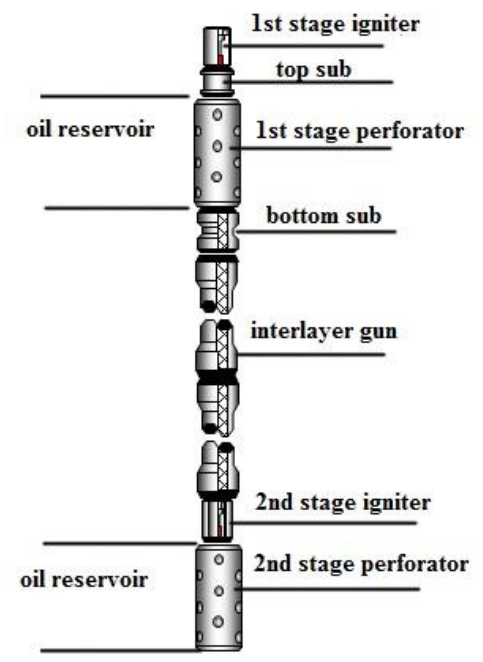

Figure 1. Conventional detonation transmission string among interlayer 
Considering the situation of detonation transmission technology among interlayer, the Pressurizing Device is developed to solve detonation transmission problem and decrease operation cost, which simplifies operation process, improve the reliability of long interlayer's operation, eliminates potential accidents and meets with the requirement of safety, reliability and environmental protection.

\section{Design Concept Of The New Detonation Transmission Technology Among Long Interlayers In Oil And Gas Well}

As Figure 1 shows, the detonation transmission technology among long interlayers consists of pressurizing device, small-hole collar and limit collar. After igniting of the primary igniter, detonation is transmitted from perforating charge to pressurizing device. The primary composite powder is ignited by the energy transfer of composite igniter, and then instantly produces high temperature and high pressure gas. After the lower mechanical part of pressurizing device opens, high pressure gas releases into interlayer tubing ${ }^{[2]}$. Interlayer tubing is full of liquid which cannot be compressed so that will instantly transmit gas pressure to next stage pressure actuated vent igniter. The output pressure of pressurizing device is higher than the required cutting pressure of next stage pressure actuated vent igniter, so the next stage igniter shall be ignited. The next stage perforating string gets accomplished $^{[3]}$.

\section{Mechanical Structure Design}

\subsection{Prepressing piston structure}

According to momentum theory and stress calculation formula, under definite variation of function period and speed, increasing the weight and area are the two methods to increase impact force of object. Based on plenty of tests, the output pressure of the pressurizing device will be increased if there is definite prepressing value before the piston being pushed out. According to this thought, the piston structure is re-designed optimally as Figure 2.

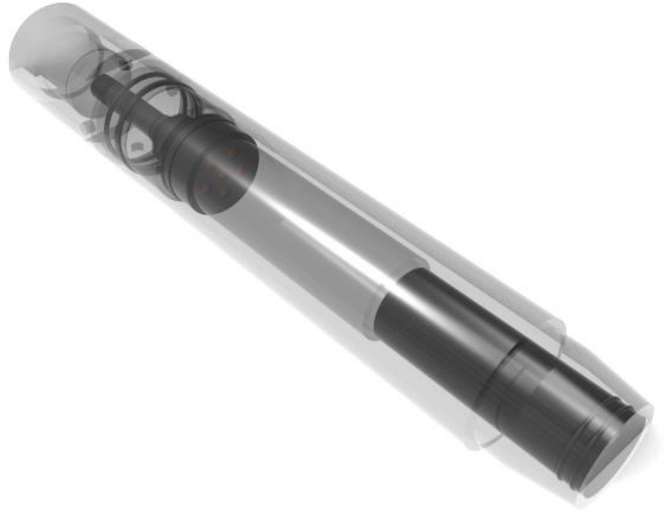

before adjusting

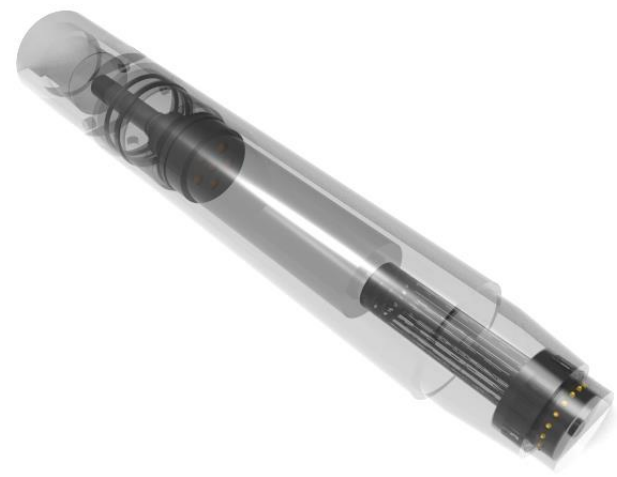

after adjusting

Figure 2. Adjusting comparison of piston structure of the new detonation transmission technology among long interlayers in oil and gas well

The adjusting process is as Figure 3. By plenty of pressure test in $130 \mathrm{~m}$ tubing and considering of feasibility and existing merit and demerit, Plan 3 and Plan 4, using assistor structure, increased the entire output pressure of pressurizing device and expanded the application range of pressurizing device to various tubing dimensions as an independent unit. Plan 4 meets with the requirement of output pressure and is convenient for operation, which is the final designed solution ${ }^{[4]}$. 


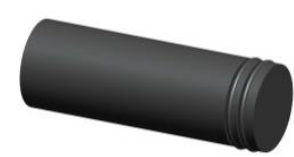

Plan 1

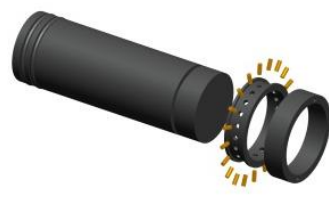

Plan 2

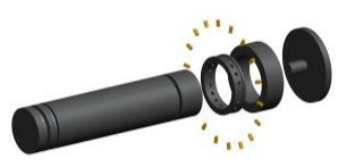

Plan 3

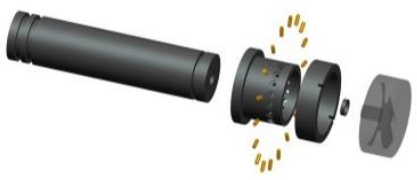

Plan 4

Figure 3. Adjusting process of piston structure

\subsection{Specialized collar design}

Specialized collar divides into big hole collar and small hole collar that is at ends of tubing. The function of specialized collar used in long interlayer strings is as followings.

a) During running of strings, well liquid is absorbed into tubing from big hole collar under the pressure difference of static liquid of tubing. Meanwhile, the remaining gas of tubing is expelled out from small hole collar and finally interlayer is full of liquid.

b) It will avoid damaging string by expelling the unnecessary gas from pressurizing device.

c) Leading the release channel of high temperature and high pressure gas to the direction of next stage pressure actuated igniter, that is the direction of big hole collar ${ }^{[5]}$.

The big hole and small hole collar is designed using in interlayer tubing that simplify operation and guarantee safety. Considering of test data, the dimension of big hole collar and small hole collar is optimally designed. The best combination is that the diameter of small hole collar being $2 \mathrm{~mm}$ and big hole collar $5 \mathrm{~mm}$.

\subsection{Limit collar design}

Because the dimension of piston and assistor is larger than the piston dimension of conventional pressurizing device, to prevent piston stop in tubing, a special tubing collar is needed to stop piston assembly, meanwhile, to guarantee normal pressure transmission of pressurizing device piston, the assembly position of collar shall be at the end of first tubing (length is more than $2 \mathrm{~m}$ ) which is connected to small hole collar. The limit collar is as Figure 4.

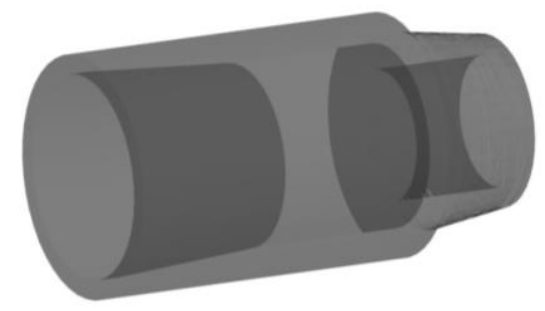

Figure 4. Limit collar structure

\section{Baffle Igniter Selection}

A suitable baffle igniter for long interlayer detonation transmission is selected for using which has the following characters: a. accomplishing the transfer from detonation to burning that is able to fire bridge powder and propellant; $b$. strong firing capability and long firing distance; $c$. having a definite pressure resistance; d. simple structure, safety and reliability. The technical parameters are as followings.

Table 1. Technical parameters of baffle igniter

\begin{tabular}{|c|c|}
\hline Max Temperature & $160^{\circ} \mathrm{C} / 48 \mathrm{~h}$ \\
\hline Max OD & $\varphi 14 \mathrm{~mm}$ \\
\hline Length & $58.5 \mathrm{~mm}$ \\
\hline Firing Distance & $120 \mathrm{~mm}$ \\
\hline
\end{tabular}




\section{Selection Of Propellant And Performance Output Test}

According to the performance requirement of pressurizing device, all the performance of propellant shall be tested, including firing under normal temperature, firing under high temperature, pressure test under sealing and pressure test in $130 \mathrm{~m}$ tubing. The normal temperature test and normal temperature test after $180^{\circ} \mathrm{C} / 100 \mathrm{~h}$ are all fired reliably. Testing result under sealing is as Table 2 .

Table 2. Testing data of pressurizing device under sealing

\begin{tabular}{|c|c|c|c|}
\hline Explosive weight/g & 50 & 70 & 80 \\
\hline Peak pressure/MPa & 50 & 89.1 & 90.9 \\
\hline
\end{tabular}

Testing result under sealing after $180^{\circ} \mathrm{C} / 100 \mathrm{~h}$ is as Table 3 .

Table 3. Testing data under sealing after $180^{\circ} \mathrm{C} / 100 \mathrm{~h}$

\begin{tabular}{|c|c|c|c|}
\hline Weight/g & 82 & 86 & 86 \\
\hline Peak pressure/MPa & 98.7 & 102.4 & 94.2 \\
\hline
\end{tabular}

Pressure testing result in $180 \mathrm{~m}$ tubing is as Table 4.

Table 4. Pressure testing data in $130 \mathrm{~m}$ tubing

\begin{tabular}{|c|c|c|c|c|c|c|}
\hline \multirow[b]{2}{*}{ No. } & \multirow[b]{2}{*}{$\begin{array}{c}\text { Cutting } \\
\text { pin } \\
\text { /piece }\end{array}$} & \multirow{2}{*}{$\begin{array}{c}\text { Confin } \\
\text {-ing } \\
\text { pressur } \\
\text { e } \\
\text { /MPa }\end{array}$} & \multicolumn{2}{|c|}{ Front end of tubing } & \multirow{2}{*}{$\begin{array}{c}\begin{array}{c}\text { Bottom } \\
\text { end of } \\
\text { tubing }\end{array} \\
\text { Testing } \\
\text { pressure } \\
\text { by } \\
\text { detector } \\
\text { 3/MPa }\end{array}$} & \multirow[b]{2}{*}{$\begin{array}{c}\text { Statu } \\
\text { s of } \\
\text { vent }\end{array}$} \\
\hline & & & $\begin{array}{c}\text { Testing } \\
\text { pressur } \\
\text { e by } \\
\text { detector } \\
\text { 1/MPa }\end{array}$ & $\begin{array}{c}\text { Testing } \\
\text { pressur } \\
\text { e by } \\
\text { detector } \\
2 / \mathrm{MPa}\end{array}$ & & \\
\hline 1 & 20 & 0 & 77.9 & 77 & 74.5 & open \\
\hline 2 & 20 & 0 & 69.4 & 68.2 & 67.2 & open \\
\hline 3 & 20 & 10 & 70.1 & 69.1 & 69 & open \\
\hline 4 & 20 & 0 & 73.3 & 71.2 & 68.2 & open \\
\hline 5 & 20 & 0 & 75.6 & 72.2 & 70.8 & open \\
\hline
\end{tabular}

Integrating former testing data and feasibility and existing merit and demerit, using assistor structure, increased the entire output pressure of pressurizing device and expanded the application range of pressurizing device to various tubing dimensions as an independent unit. By plan 4' $\mathrm{s}$ pressure test in $130 \mathrm{~m}$ tubing, the pressurizing device can meet the requirement of $180^{\circ} \mathrm{C} / 48 \mathrm{~h}$ temperature resistance, $100 \mathrm{MPa}$ pressure resistance, $\leq 70 \mathrm{MPa}$ pressure difference output and $\geq 30 \mathrm{MPa}$ pressure difference at $100 \mathrm{~m}$ point to output side.

\section{Development Tendency Of Detonation Transmission Technology Among Long Interlayer}

With simple structure and high output power, pressurizing device can be widely used in long interlayer detonation transmission technology. No matter how the structure and design parameter changes, the final purpose is for actual application. Summarizing the design process, the followings of interlayer detonation transmission needs to be attended.

(1) Pressurizing device uses in-forcibility of liquid for detonation transmission, however, because of the non-certainty of powder and in-forcibility of liquid, the output performance has a range, but not a certain value, which leads non-certainty of interlayer detonation transmission. By the continuous progress of intelligent technology, the detonation transmission among interlayer is possible to be improved step by step.

(2)Pressurizing device uses explosive function for detonation transmission, however, there are other explosives during operation, such as perforating charge and fracturing powder. If fracturing powder instantly works; it produces a high pressure difference between casing and tubing; pressurizing device re-works and produces a high pressure which will cause break of tubing and accident. In long interlayer detonation transmission, deleting explosive is a thought for future development. 


\section{Conclusions}

According to the required detonation transmission technology among long interlayer, this paper develops the pressurizing device. The device meets the required technical parameters for use, with reliable performance, safety and reliable function. Comparing with conventional TCP operation in actual application, the pressurizing device in interlayer has the following advantages.

(1)Reliability

In conventional TCP interlayer operation, it requires sealing of interlayer gun and transmission sub and reliability of detonating cord and booster. However, in pressurizing device in interlayer operation, interlayer tubing is instead of interlayer gun without sealing requirement; detonation transmission points is decreased so that the reliability is improved. So success rate is largely increased.

(2)Economic efficiency

Simple operation; low labor strength; shorter operation period and saving cost. Interlayer can be re-used.

\section{References}

[1] Z. Zhou. Study on detonation propagation in TCP perforated section. Initiating explosive device 3 (1997):35-38.

[2] W. H. Lee. Oil well perforator design using 2D Eulerian code[J] . International Journal of Impact Engineering . 2002 (5).

[3] X.J. Liu, R.W. Chen. Current status and development trend of piezoelectric vibration energy harvesting device [J]. Vibration and device, 2012, 31(16):169-176.

[4] Inversion of P-wave VSP data for local anisotropy: Theory and case study. Grechka, Vladimir,Mateeva, Albena. Geophysics . 2007.

[5] Structural Design Method on Elastic-plastic of Oil Perforating Guns, Proceedings of 2010 International Conference on Computer, Mechatronics, Control and Electronic Engineering (CMCE 2010) Volume 3.08 (2010) 12-15. 